\title{
Hybrid Model based on Peltier and Piezoelectric Human Energy Harvesting for WBAN Application
}

\author{
Hardeep Singh Dhillon, Paras Chawla
}

\begin{abstract}
Wireless body area network (WBAN) is developed as a result of Wireless personal area network (WPAN), in which various interconnected Body Node (BN) communicates near and around human body. There are many differences between the WBAN and WPAN i.e distribution, density and mobility. Due to redundant nodes, BN in WBAN are less dense. In WBAN, Body node are implanted inside and on human body to measure physiological signals using different sensors i.e Electro cardio graph (ECG), electroencephalogram (EEG), Blood pressure, temperature etc) of body which collects data and send it to sink node. Earlier researchers have used either piezoelectric harvester, solar or temperature gradient based. But in this paper optimization technique using combination of Peltier and Piezoelectric human energy harvesting is studied. By developing an algorithm, extensive simulation can be performed considering four human body gestures (relaxing, walking, running and fast running). Overall Quality of Service (QoS) including average (packet loss, end-to-end delay, throughput) and overall detection efficiency is studied.
\end{abstract}

Index Terms: Wireless body area network, QoS, Optimization, Piezoelectric, Peltier.

\section{INTRODUCTION}

In Wireless Sensor Networks (WSNs) a group sensors are spatially distributed that monitor and analyze the physical conditions of the environment. It can measure various environmental conditions for example temperature, sound, humidity, wind, and so on. The WSNs have very broad area of research but currently only data communication with low data rates and short range small sensor node having low power consumption with cheap devices are covered. Depending on the application Wireless Sensor Network (WSN) may have some or many nodes whose range may vary from a few to several hundreds or thousands. Moreover there is a interconnection between each and every nodes depending on the applications. Nodes designed in WSN may be used to carry out one or more than one function including sensing, relaying data, or exchanging data within or outside network. A node that sense data is called a sensor node. On the other hand relaying of data is done by a router, and a base station or sink node is used for exchanging data with other networks, like a gateway does in a traditional network. Every sensor

Revised Manuscript Received on July 09, 2019.

Hardeep Singh Dhillon, Ph.D research scholar, Department of ECE, Chandigarh University, Gharuan, Mohali, India

Prof (Dr.) Paras Chawla, HOD, Department of ECE, Chandigarh University, Gharuan, Mohali, India node consists of a transducer, a microcontroller, a radio transreceiver and a power supply, usually a battery energy density to allow implementations with low cost, long lifetime etc. So it is practically not possible to change battery every time in most of applications including biomedical applications in which it may affect the health of patient when $\mathrm{BN}$ is implanted inside human body. Battery capacity can also be increased by increasing size of battery but it may affect health of person. Hence the concept of Energy harvesting is included. In energy harvesting $[7,8,9] \mathrm{BN}$ battery is charged by ambient sources i.e vibration, motion, light, heat etc. WBAN suffers from interference due to very small distance between Body node which result in serious interference and decrease in Quality of service (QoS) [10]. There are many differences between the WBAN and WPAN i.e distribution, density and mobility. Due to redundant nodes BN in WBAN are less dense. Power consumption in WBAN is less as compared to WPAN.

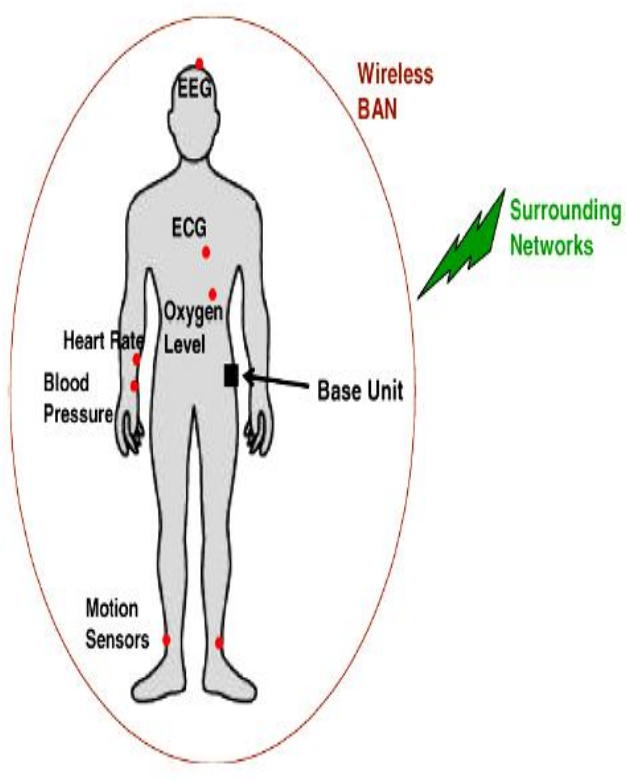

Figure- 1 Wireless body area network

Intelligent Body nodes [3] collect various physiological signals of human body. Nodes first sense signal then sample, process and finally communicate it to Body node coordinator (BNC) $[4,5]$ also called master node. Generally BNC is a smart phone or Personal Computer (PC) having an external power supply. Data rate in WBAN is generally between 1 Kbps- $10 \mathrm{Mbps}$. WBAN as shown in Figure- 1 comprises of different types of miniature sensors either worn on athlete, patient or soldier. 


\section{Hybrid Model based on Peltier and Piezoelectric Human Energy Harvesting for WBAN Application}

BN has limited power source i.e battery generally a super capacitor. But after some time as battery level drops BN stops working. Battery [6] do not provide sufficient energy density to allow implementations with low cost, long lifetime etc. So it is practically not possible to change battery every time in most of applications including biomedical applications in which it may affect the health of patient when BN is implanted inside human body. Battery capacity can also be increased by increasing size of battery but it may affect health of person. Hence the concept of Energy harvesting is included. In energy harvesting $[7,8,9] \mathrm{BN}$ battery is charged by ambient sources i.e vibration, motion, light, heat etc. WBAN suffers from interference due to very small distance between Body node which result in serious interference and decrease in Quality of service (QoS) [10]. Extensive simulation can be performed considering four different human gestures (relaxing, walking, running and fast running).

\section{A. Internet of Thing (IoT)}

The internet of things is regarded as one of the most innovative technology in recent years. It has drawn great interest in both academia and industries [1,2]. In the IoT world, individuals are connected to this "smart" ecosystem by "smart" things, which could be a laptop, a mobile phone, or a wireless sensor. With a wide range of modern technologies involved, including sensors and actuators, Microsystems, wireless communications, big data and more, the IoT plays an essential role to define and transform the way people live and work, bringing extraordinary benefits to industries and daily life $[2,3]$. One significant enabler of the IoT is the wireless sensor network. With continuous miniaturization and cost reduction of electronic components and a rapid growth of wireless sensing technology, IoT and WSNs are expected to bring even more benefits in the near future.

\section{WBAN ARCHITECTURE}

WBAN consists of various interconnected body sensor nodes, which can either be placed in or around the human body [1] depending on application. As shown in Figure- 2 WBAN architecture consists of three tiers i.e Intra BAN, Inter BAN and Beyond WBAN communication.

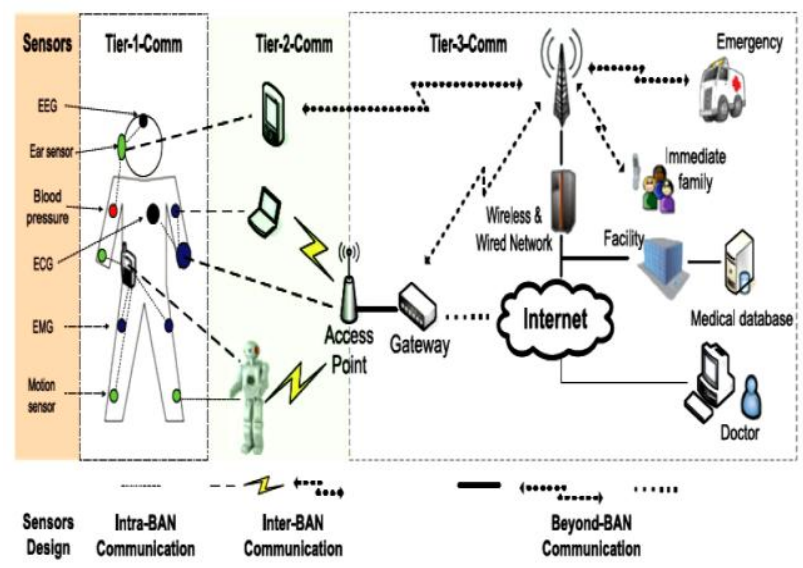

Figure- 2: Three-tier architecture based of WBAN

In Intra BAN [11] communication range is 2 meter around person. In Intra WBAN two types of communication occurs between body sensor node also called BN (Body Node) and sink BSN (Body Sensor Node) and between BN and BNC (Body node coordinator) also called Master Node which is generally a Smart Phone or Computer. A sensor node collects data and sends it to BNC wirelessly.

\section{A. IEEE 802.15.6}

IEEE 802.15.6 [12] is used as a standard internationally to develop communication model between low power devices implanted inside or placed on human body and this network is known as WBAN. IEEE 802.15.6 defines international standard in term of short range, low power wireless communication. It uses international scientific medical (ISM) band as well as frequency band approved by national medical as regulatory authority. Sensor and reader is based on $30 \mathrm{uW}$ analog signal processor and trans-receiver employ $1.9 \mathrm{~nJ} / \mathrm{b}$ at $2.4 \mathrm{GHz}$ processor which support extremely low power data rate $10 \mathrm{Mbps}$.

\section{ENERGY HARVESTING}

Since battery has finite power supply so concept of Energy Harvesting $(\mathrm{EH})$ is introduced. For energy harvesting the node should be in Energy neutral state (ENO) i.e energy harvested should be more than energy consumed. In EH energy is harvested from source internally i.e, peltier, piezo-electric [13] and externally solar, thermal etc to charge BN battery. Such harvesters continuously generate small amount of energy and gives higher output energy. Earlier researcher has used piezo, solar etc and used one harvester in body node for WBAN but proposed work is to use 4 body nodes for ECG and a new harvester peltier harvester with piezoelectric in order to increase collected amount of energy. Hence model namely hybrid optimization of piezo and pelier is proposed by controlling the on-off timing of body nodes during various gestures including relaxing, walking, running and fast running.

\section{SOURCES OF AMBIENT ENERGY HARVESTERS}

In energy harvesting technique there are many energy harvesters but high power source is preferred. Energy harvester should be such that it saves more power and less cost. Various energy source are solar, RF, thermal, vibration etc.

\section{A. Thermal Harvester}

It is based on concept of see beck effect/peltier effect i.e in this harvester energy is generated by difference in temperature/temperature gradient between two pins of peltier sensor. In Peltier effect when junctions of two materials are applied voltage, it absorbs heat at one end and dissipate at the other. This effect produces power as long as heat is present. For generating adequate output power temperature difference should be large. Thermal variation produces energy up to $10 \mathrm{uW} / \mathrm{cm}^{2}$. The thermocouple is included as a basic element, as shown in Figure- 3. A thermocouple semiconductor material consists of both P-type and N-type with metallic connections.

Figure- 3: Thermocouple.

Published By Blue Eyes Intelligence Engineering \& Sciences Publication 


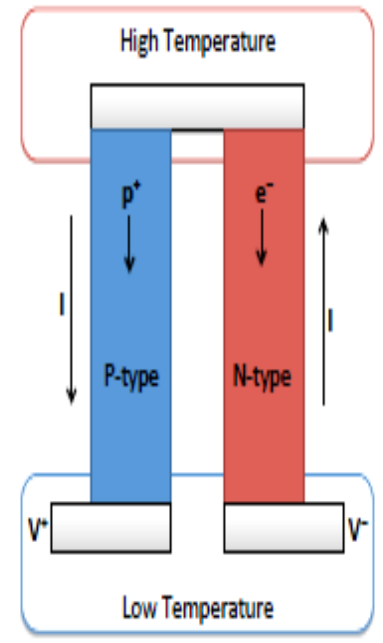

The charge carriers diffuse due to the temperature difference at the opposite sides of the materials. Carriers including both electrons and hole moves from the hotter side towards the cold. This in turn forms an electrical potential, and current flows when circuit is closed.

\section{B. Vibration harvester}

Generally piezo sensor is used to harvest energy in this category. Its output varies from $10-100 \mathrm{~mW} / \mathrm{cm}^{2}$. Piezo-electric sensor is placed below foot of human and signal is generated when pressure is applied during foot motion. Energy harvested is converted into electric energy. The quartz being most famous which generates electrical charges when pressure is applied also known as piezoelectricity.

\section{Light Harvester}

Energy harvesting from ambient light is the approach to convert photonics energy to direct current electrical power by photovoltaic (PV) [20]. PV is the technology based on the photovoltaic effect, in which semiconductors can generate electrical power when they are illuminated by light (photons) $[20,21]$. Harvesting energy from ambient light is a relatively mature method compared to others [8]. The essential source for energy harvesting of this kind is the solar energy and a solar cell module. Figure- 4, shows a generic solar cell comprising a PN junction, an anti-reactive layer, and metal contacts as electrodes.

When sunlight falls on the top layer, the photon can travel to the PN junction, and if the photons are able to excite free electrons and create electron hole pairs which in turn generate electrical power from the solar cell. Recent work in light/solar energy harvesting shows that the practical power efficiency of solar cells is approximately $10 \%$ [22-24], and some research work has reported higher efficiencies, such as the one from Repinset al. [25].
Innovative Technology and Exploring Engineering (IJITEE)

ISSN: 2278-3075, Volume-8, Issue-9S, July 2019

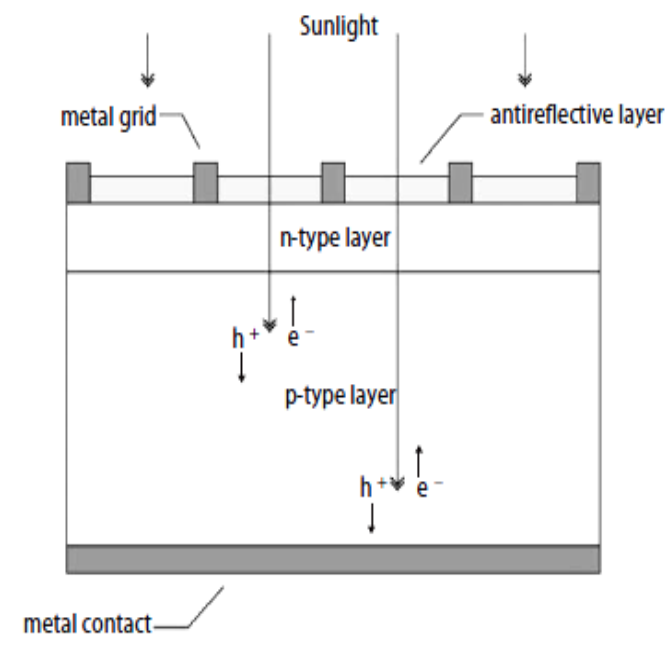

Figure- 4: Schematic of a simple solar cell [20].

With a practical efficiency of $\sim 10 \%$, the solar cell can achieve a power density of more than $10 \mathrm{~mW}=\mathrm{cm}^{2}$ outdoors under direct sunlight, but the output power could be as low as $\sim 10$ $\mu \mathrm{W}=\mathrm{cm}^{2}$ when it is cloudy outdoors or the device is located indoors [26], which exposes the disadvantage of the light/solar energy harvesting. In spite of this, light/solar energy harvesting is a viable option in many applications when sunlight is sufficient, but has limited performance for body sensing applications especially for implanted devices.

\section{Radio Frequency}

The ambient Radio Frequency (RF) power is collected with an antenna system. The premise of Radio Frequency energy harvesting is to investigate efficient RF energy sources available in environment, and most interestingly sources from broadcasting stations like GSM900, GSM1800, TV, WiFi, etc. [36-38]. Similar to RF energy harvesting, RF power delivery with dedicated sources has been commercially available recently, especially for wireless charging of portable devices like mobile phones and wrist bands. Practical implementations for wireless sensing and body sensing, will involve more efforts to design suitable sources apart from the receiving (harvesting) modules. In addition, health issues are a major concern when RF power delivery is considered in medical applications [42].

\section{POWER ENERGY AWARE MANAGEMENT QOS}

There are three modules which include Power management, Data queue, and Packet compression.

i) Power Management: It manages harvested energy and keep node in Energy neutral operation (ENO) to obtain lifetime power for data detection and Transmission. Moreover node is said to be in ENO state if it consume less or equal amount of energy compared to the total energy harvested from environment.

ii) Data Queue: Data queue module take care that only useful data is transmitted in time constraint. When data is transmitted in queue a fixed no of packets are allowed to be transmitted and the packets that are delayed above fixed delay 


\section{Hybrid Model based on Peltier and Piezoelectric Human Energy Harvesting for WBAN Application}

threshold which are now irrelevant are ignored and not transmitted.

iii) Packet Compression: In this step duplicate data packet address is transmitted instead of duplicate packet hence decrease in data congestion during transmission.

\section{DATA COLLECTION}

A new method is proposed by developing algorithm for hybrid optimization of piezo and peltier by controlling on off timing of $\mathrm{BN}$ operation for various gestures including sitting, walking, running and fast running. By considering two harvesters average power reading as shown in Table I \& Table II and four BN nodes placed at four different positions of human body is studied.

Table I. Average energy harvested by piezoelectric harvester (mW)

\begin{tabular}{|c|c|c|c|c|}
\hline$Z_{\infty}$ & 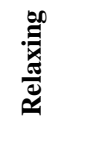 & 照 & 兰 & 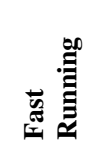 \\
\hline 1 & 19.989 & 124.986 & 252.139 & 302.807 \\
\hline 2 & 20.028 & 125.111 & 252.014 & 301.863 \\
\hline 3 & 19.963 & 124.815 & 252.246 & 302.123 \\
\hline 4 & 20.016 & 125.099 & 252.458 & 302.260 \\
\hline
\end{tabular}

Table II. Average energy harvested by peltier harvester (mW)

\begin{tabular}{|c|c|c|c|c|}
\hline$Z_{0}$ & & 葛 & 哭 & 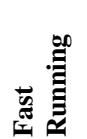 \\
\hline 1 & 2.992 & 7.480 & 10.979 & 20.045 \\
\hline 2 & 3.011 & 7.521 & 11.032 & 20.024 \\
\hline 3 & 3.007 & 7.510 & 11.012 & 19.963 \\
\hline 4 & 2.982 & 7.481 & 11.045 & 19.969 \\
\hline
\end{tabular}

\section{CONCLUSION}

In this paper various techniques of energy harvesting is studied and by developing an algorithm using combination of Peltier and Piezoelectric human energy harvesting is studied. By developing an algorithm, extensive simulation can be performed considering four human body gestures (relaxing, walking, running and fast running). Overall QoS including average (packet loss, end-to-end delay, and throughput) and overall detection efficiency is studied.

\section{FUTURE SCOPE}

In future multi-energy harvesters can be used. Till now researchers has done harvesting using one harvester with body node so in future two or more than two harvesters can be placed on human body interconnected with various body node which can be placed in WBAN according to the application. Present energy harvesting can be modified in in following ways:

1) Source energy harvester will transmit harvested energy to that node which requires it instantaneously.

2) Concept of feedback and threshold can be introduced so that most reliable source is selected.

3) Priority is set so that most needy node get energy first and then other one in queue.

When energy required is more than two or more harvester energy is added and supplied to that node.

\section{REFERENCES}

1] Mainwaring, Alan 'Wireless sensor networks for habitat monitoring.' Proceedings of the 1st ACM international workshop on Wireless sensor networks and applications. ACM, 2002.

2] Y.-T. Lin, Y.-S. Lin, C.-H. Chen, H.-C. Chen, Y.-C. Yang, and S.-S. Lu, 'A $0.5-\mathrm{V}$ biomedical system-on-a-chip for intrabody communication system,' IEEE Trans. Ind. Electron., vol. 58, no. 2, pp. 690-699, Feb. 2011.

3] N. Javaid, Z. Abbas, M. S. Farid, Z. A. Khan and N. Alrajeh, "M-ATTEMPT: A New Energy-Efficient Routing Protocol for Wireless Body Area Sensor Networks", The 4th International Conference on Ambient Systems, Networks and Technologies (ANT 2013), 2013 Halifax, Nova Scotia, Canada, Procedia Computer Science, Volume 19, 2013, Pages 224-231, ISSN 1877-0509, http://dx.doi.org/10.1016/j.procs.2013.06.033. Procedia Computer Science.

4] Kovacevic, T., T. Perkovic, and M. Cagalj. "LIRA: A new key deployment scheme for Wireless Body Area Networks." In Software, Telecommunications and Computer Networks (SoftCOM), 2013 21st International Conference on, pp. 1-6. IEEE, 2013.

5] Javaid, N.; Bibi, A.; Djouani, K., "Interference and bandwidth adjusted ETX in wireless multi-hop networks," GLOBECOM Workshops (GC Wkshps), 2010 IEEE , vol., no., pp.1638,1643, 6-10 Dec. 2010. doi 10.1109/GLOCOMW.2010.5700217.

6] SH. Lee, JJ. Yoo and TC. Chuan, "Distance-based Energy Efficient Clustering for Wireless Sensor Networks", Proc. of the 29th IEEE Int ${ }^{\text {ec }}$ Conf. on Local Computer Networks ( $\left.\mathrm{LCN}^{\mathrm{ee}} 04\right)$.

7] Di Renzo, M.; Buehrer, R.; Torres, J. "Pulse Shape Distortion and Ranging Accuracy in UWB-Based Body Area Networks for Full-Body Motion Capture and Gait Analysis". In Proceedings of the IEEE Global Telecommunications Conference (GLOBECOM 2007), Washington DC, WA, USA, 26-30 November 2007; pp. 3775-3780.

8] Sana Ullah, Pervez Khan, Niamat Ullah, Shahnaz Saleem, Henry Higgins, and Kyung Sup Kwak "A Review of Wireless Body Area Networks for Medical Applications” arXiv:1001.0831v3 [cs.NI] 3 Aug 2010.

9] Momoda, Miyu, and Shinsuke Hara. "Use of IEEE 802.15. 4e for a cooperator-assisted wireless body area network." In Medical Information and Communication Technology (ISMICT), 2014 8th International Symposium on, pp. 1-5. IEEE, 2014.

10] Ming Liu, Jiannong Cao, Guihai Chen 3 and Xiaomin Wang "An Energy-Aware Routing Protocol in Wireless Sensor", ISSN 1424-8220, Networks, SENSORS 2009

11] P. Spachos and D. Hantzinakos, "Scalable dynamic routing protocol for cognitive radio sensor networks," IEEE Sensors J., vol. 14, no. 7,pp. 2257-2266, Jul. 2014.

12] Heinzelman, Wendi Rabiner, Anantha Chandrakasan, and Hari Balakrishnan. "Energy-efficient communication protocol for wireless microsensor networks." System Sciences, 2000. Proceedings of the 33rd Annual Hawaii International Conference on. IEEE, 2000.

13] P. Li, Y. Wen, W. Yin, and $H$. $\mathrm{Wu}$, "An upconversion management circuit for low-frequency vibrating energy harvesting," IEEE Trans. Ind. 
Electron., vol. 61, no. 7, pp. 3349-3358, Jul. 2014

14] M. Lossec, B. Multon, and H. B. Ahmed, "Sizing optimization of a thermoelectric generator set with heat sink for harvesting human body heat," Energy Conversion and Management, vol. 68, pp. 260- 265, 2013.

15] V. Leonov, "Thermoelectric energy harvesting of human body heat for wearable sensors," Sensors Journal, IEEE, vol. 13, no. 6, pp. 2284-2291, 2013.

16] M.-K. Kim, M.-S. Kim, S. Lee, C. Kim, and Y.-J. Kim, "Wearable thermoelectric generator for harvesting human body heat energy," Smart Materials and Structures, vol. 23, no. 10, p. 105002, 2014.

17] A. Almusallam, R. Torah, D. Zhu, M. Tudor, and S. Beeby, "Screenprinted piezoelectric shoe-insole energy harvester using an improved exible PZT-polymer composites," in Journal of Physics: Conference Series, vol. 476, no. 1. IOP Publishing, 2013, p. 012108. 146.

18] J. Kymissis, C. Kendall, J. Paradiso, and N. Gershenfeld, "Parasitic power harvesting in shoes," in Wearable Computers, 1998. Digest of Papers. Second International Symposium on. IEEE, 1998, pp. 132-139.

$19]$ N. S. Shenck and J. A. Paradiso, "Energy scavenging with shoe mounted piezoelectrics," IEEE micro, no. 3, pp. 30-42, 2001.

20] A. Luque and S. Hegedus, "Handbook of photovoltaic science and en-gineering" John Wiley \& Sons, 2011.

21] R. Bube, "Fundamentals of solar cells: photovoltaic solar energy conversion" Elsevier, 2012

22] J. You, L. Dou, K. Yoshimura, T. Kato, K. Ohya, T. Moriarty, K. Emery, C.-C. Chen, J. Gao, G. Li et al., "A polymer tandem solar cell with $10.6 \%$ power conversion effciency," Nature communications, vol. 4, p. 1446,2013

23] H.-S. Kim, C.-R. Lee, J.-H. Im, K.-B. Lee, T. Moehl, A. Marchioro, S.-J. Moon, R. Humphry-Baker, J.-H. Yum, J. E. Moser et al., "Lead iodide perovskite sensitized all-solid-state submicron thin film mesoscopic solar cell with effciency exceeding 9\%," Scientific reports, vol. 2, 2012.

24] D. A. R. Barkhouse, O. Gunawan, T. Gokmen, T. K. Todorov, and D. B. Mitzi, "Device characteristics of a $10.1 \%$ hydrazine-processed $\mathrm{Cu} 2 \mathrm{ZnSn}(\mathrm{Se}, \mathrm{S}) 4$ solar cell," Progress in Photovoltaics: Research and Applications, vol. 20, no. 1, pp. 6-11, 2012.

25] I. Repins, M. A. Contreras, B. Egaas, C. DeHart, J. Scharf, C. L. Perkins, B. To, and R. Noufi, "19.9\%-effcient $\mathrm{ZnO} / \mathrm{CdS} / \mathrm{CuInGaSe} 2$ solar cell with $81.2 \%$ fill factor," Progress in Photovoltaics: Research and applications, vol. 16, no. 3, pp. 235-239, 2008.

26] S. Roundy, E. S. Leland, J. Baker, E. Carleton, E. Reilly, E. Lai, B. Otis, J. M. Rabaey, P. K. Wright, and V. Sundararajan, "Improving power output for vibration-based energy scavengers," Pervasive Computing, IEEE, vol. 4, no. 1, pp. 28-36, 2005. 147

27] K. Uchida, S. Takahashi, K. Harii, J. Ieda, W. Koshibae, K. Ando, S. Maekawa, and E. Saitoh, "Observation of the spin Seebeck effect," Nature, vol. 455, no. 7214, pp. 778-781, 2008.

$28]$ D. M. Rowe, "Thermoelectrics handbook: macro to nano." CRC press, 2005

29] O. Bubnova, Z. U. Khan, A. Malti, S. Braun, M. Fahlman, M. Berggren, and $\mathrm{X}$. Crispin, "Optimization of the thermoelectric figure of merit in the conducting polymer poly (3, 4- ethylenedioxythiophene)," Nature materials, vol. 10, no. 6, pp. 429- 433, 2011.

30] Y. Pei, A. LaLonde, S. Iwanaga, and G. J. Snyder, "High thermoelectric figure of merit in heavy hole dominated PbTe," Energy \& Environmental Science, vol. 4, no. 6, pp. 2085-2089, 2011.

31] D. Kraemer, B. Poudel, H.-P. Feng, J. C. Caylor, B. Yu, X. Yan, Y. Ma, X. Wang, D. Wang, A. Muto et al., "High-performance atpanel solar thermoelectric generators with high thermal concentration," Nature materials, vol. 10, no. 7, pp. 532-538, 2011.

32] H. Alam and S. Ramakrishna, "A review on the enhancement of figure of merit from bulk to nano-thermoelectric materials," Nano Energy, vol. 2, no. 2, pp. 190-212, 2013.

33] R. Saidur, M. Rezaei, W. Muzammil, M. Hassan, S. Paria, and M. Hasanuzzaman, "Technologies to recover exhaust heat from internal combustion engines," Renewable and Sustainable Energy Reviews, vol. 16, no. 8, pp. 5649-5659, 2012.

34] Y. Hsiao, W. Chang, and S. Chen, "A mathematic model of thermoelectric module with applications on waste heat recovery from automobile engine," Energy, vol. 35, no. 3, pp. 1447-1454, 2010.

35] H. Lu, T.Wu, S. Bai, K. Xu, Y. Huang, W. Gao, X. Yin, and L. Chen, "Experiment on thermal uniformity and pressure drop of exhaust heat exchanger for automotive thermoelectric generator," Energy, vol. 54, pp. 372-377, 2013. 148.

36] X. Gao, S. J. Andreasen, M. Chen, and S. K. Kaer, "Numerical model of a thermoelectric generator with compact plate-fin heat exchanger for high temperature pem fuel cell exhaust heat recovery," interna- tional journal of hydrogen energy, vol. 37, no. 10, pp. 8490-8498, 2012
37] B. Xu and K. Fobelets, "Effciency improvement of silicon nanowire arrays (NWAs) thermoelectric power generation (TEG) by spin on doping (SOD)," in Meeting Abstracts, no. 4. The Electrochemical Society, 2013, pp. 279-279.

38] B. Xu, C. Li, K. Thielemans, M. Myronov, and K. Fobelets, "Thermoelectric performance of nanowire arrays," Electron Devices, IEEE Transactions on, vol. 59, no. 12, pp. 3193-3198, 2012.

39] S. K. Yee, N. E. Coates, A. Majumdar, J. J. Urban, and R. A. Segalman, "Thermoelectric power factor optimization in PEDOT: PSS tellurium nanowire hybrid composites," Physical Chemistry Chemical Physics, vol. 15, no. 11, pp. 4024-4032, 2013.

40] C.-C.Wang, C.-I. Hung, and W.-H. Chen, "Design of heat sink for improving the performance of thermoelectric generator using two-stage optimization," Energy, vol. 39, no. 1, pp. 236-245, 2012.

41] J. Xiao, T. Yang, P. Li, P. Zhai, and Q. Zhang, "Thermal design and management for performance optimization of solar thermoelectric generator," Applied Energy, vol. 93, pp. 33-38, 2012.

42] V. Leonov, P. Fiorini, S. Sedky, T. Torfs, and C. Van Hoof, "Thermoelectric mems generators as a power supply for a body area network," in Solid-State Sensors, Actuators and Microsystems, 2005. Digest of Technical Papers. TRANSDUCERS'05. The 13th International Con-ference on, vol. 1. IEEE, 2005, pp. 291-294.

\section{AUTHORS PROFILE}

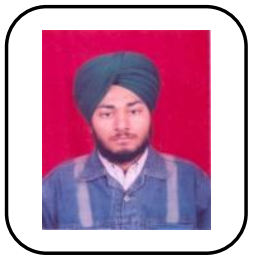

Hardeep Singh Dhillon was born in village Sundran P.O Mubarikpur Tehsil Dera Bassi MOHALI Punjab INDIA on April 6 1986. He is $\mathrm{Ph} . \mathrm{D}$ ECE final year research scholar (Univ Roll No-15YEC1005 at CHANDIGARH UNIVERSITY, Gharuan Mohali INDIA and successfully completed M.E (EPDT) univ roll-0820808 ( 2008-10 batch) at P.E.C University of Technology, Chandigarh Sector-12, Chandigarh-160012, INDIA and has completed his Thesis at Center of Advanced learning and Computing Mohali, A-34, Sector-71 Mohali-160071, PUNJAB, INDIA. He has Published (3 IEEE + 2 Nationals) research paper in conferences and one international journals.

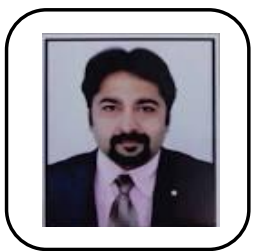

Prof (Dr.) Paras Chawla, HOD, ECE Deptt at CHANDIGARH UNIVERSITY Gharuan. Dr. Paras Chawla was born in Uttar Pradesh, India on 15th Nov., 1979. He received B.Tech. (Honors) and M.Tech. degree from the Deptt. of Electronics and Comm. Engg. at Kurukshetra University and NIT, Kurukshetra in 2003 and 2008, respectively. He received Ph.D. degree from the Deptt. of Electronics and Comm. Engg. at Thapar University, Patiala in 2015. He is currently working as Professor in Department of Electronics and Comm. Engg. at Chandigarh Engineering college, Landran, Mohali (India) and more than 13 years teaching experience. He has published more than 50 papers in various reputed National and International Journals/Conferences, one book chapter, two patents filled and two patents communicated. 